\title{
MEASURING THE INTELLECTUAL CAPITAL EFFICIENCY OF INDIAN HOTELS LISTED IN NATIONAL STOCK EXCHANGE OF INDIA LTD USING E-VAIC MODEL
}

\author{
Vadivel Thanikachalam, Bharathidasan University, India \\ Murugesan Selvam, Bharathidasan University, India \\ Balasundram Maniam, Sam Houston State University, U.S.A.
}

dx.doi.org/10.18374/JIFE-20-1.6

\begin{abstract}
The purpose of this study is to determine whether intellectual capital (IC) impacts the profitability of the Indian hotel industry. Specifically, this paper examines the degree to which IC and its key components affect the profitability performance of hotels. The sample included all the hotels that are listed in the NSE. Extended value-added intellectual coefficient was used to measure the level of IC contribution to the profitability of sample hotels. The results indicated that profitability was affected by relational and structural capital. The research confirmed that the return on sales of hotels in India was influenced by the efficient use of intellectual capital. The senior managers in the hotel industry must recognize the importance of managing the intangible resources embedded in their employees and processes. The findings of this study could help the recognition of the importance of investing in intellectual capital, (by hotel industry), in India. Moreover, the study suggests that long-term growth of hotels should not rely solely on physical and financial assets.
\end{abstract}

Keywords: Hotel Industry, Intellectual Capital, Profitability, Intangible Assets, and Extended Value-Added Intellectual Coefficient 